\title{
EXISTENCE OF POSITIVE SOLUTIONS FOR COUPLED SYSTEMS OF HALF-LINEAR BOUNDARY VALUE PROBLEMS INVOLVING CAPUTO FRACTIONAL DERIVATIVES
}

\author{
Yousef GHOLAMI AND KAZEM GHANBARI
}

\begin{abstract}
In this paper, we study coupled systems of the half-linear boundary value problems involving left sided Caputo fractional derivatives. The main goal of this paper is restricted to the existence verification of positive solutions for mentioned fractional boundary value problems. To this aim we use nonlinear alternative of Leray-Schauder and Krasnoselskii-Zabreiko fixed point theorems. At the end we present some numerical examples to illustrate the obtained theoretical results.
\end{abstract}

Mathematics subject classification (2010): 26A33, 34B15, 34B18.

Keywords and phrases: Fractional derivatives and integrals, boundary value problems, half-linear differential equations, fixed point theorem, positive solutions.

\section{REFERENCES}

[1] BAShir AhMAD, JUAn J. Nieto, Existence results for a coupled system of nonlinear fractional differential equations with three point boundary conditions, Comput. Math. Appl., vol. 58, (2009), pp. $1838-1843$.

[2] Z. BAI, H. LU, Positive solutions for boundary value problem of nonlinear fractional differential equations, J. Math. Anal. Appl., vol. 311, (2005), pp. 495-505.

[3] K. DieTheLm, The analysis of fractional differential equations, Springer, (2010).

[4] Sougata Dhar, QIngKaI Kong, Liapunov-type inequalities for third-order half-linear equations and applications to boundary value problems, Nonlinear Anal. Theory, Methods and Applications, vol. 110, (2014), pp. 170-181.

[5] O. DošĹY, PAVEL ŘEHÁK, Half-linear differential equations, North-Holland mathematics studies, Elsevier science, 202, (2005).

[6] KAZEM GHANBARI, Yousef Gholami, Existence and multiplicity of positive solutions for a coupled system of perturbed nonlinear fractional differential equations, Computational Methods for Differential Equations, vol. 1, no. 1, (2013), pp. 39-54.

[7] Yousef Gholami, KaZem Ghanbari, On solvability of fractional coupled hybrid systems, Asia Pacific Journal of Mathematics, 2, no. 1, (2015), pp. 54-68.

[8] Yousef Gholami, KaZem Ghanbari, Existence and uniqueness of positive solutions for coupled systems of fractional $\Delta$-difference boundary value problems, Journal of Fractional calculus and Applications, vol. 7, no. 2, (2016), pp. 88-100.

[9] Y. GHOLAMI, Existence results of positive solutions for boundary value problems of fractional order with integro-differential boundary conditions, Differ. Equ. Appl., vol. 6, no. 1, (2014), pp. 59-72.

[10] Y. GHOLAmI, Existence of an unbounded solution for multi-point boundary value problems of fractional differential equations on an infinite domain, Fractional. Differ. Calc., vol. 4, no. 2, (2014), pp. 125-136.

[11] A. A. Kilbas, H. M. SRivastava, J. J. Trujillo, Theory and Applications of fractional Differential Equations, North-Holland mathematics studies, Elsevier science, 204, (2006).

[12] N. Kosmatov, Solutions to a class of nonlinear differential equations of fractional order, Electron. J. Qual. Theory Differ. Equ., no. 20, (2009), pp. 1-10. 
[13] K. S. Miller, B. Ross, An Introduction to fractional calculus and fractioal differential equation, John Wiley, New York, (1993).

[14] K. B. Oldham, J. Spanier, The fractional calculus, Academic Press, New York, (1974).

[15] LIJUN PAN, Existence and multiplicity results for the boundary value problem of nonlinear fractional differential equations, Fractional. Differ. Calc., vol. 5, no. 2, (2015), pp. 151-162.

[16] K. R. PARs AD, B. M. B. Krushna, Positive solutions to iterative systems of fractional ordr threepoint boundary value problems with Riemann-Liouville derivative, Fractional. Differ. Calc., vol. 5, no. 2, (2015), pp. 137-150.

[17] I. Podlubny, Fractional Differential Equations, Mathematics in Science and Applications, Academic Press, New York, 19, (1999).

[18] Mujeeb UR Rehman, Rahmat Ali Khan, A note on boundary value problems for a coupled system of fractional differential equations, Comput. Math. Appl., vol. 61, (2011), pp. 2630-2637.

[19] K. SHAH, S. ZEB, R. Ali KHAN, Existence and uniqueness of solutions for fractional order m-point boundary value problems, Fractional, Differ. Calc., vol. 5, no. 2, (2015), pp. 171-181.

[20] S. ZHANG, Positive solutions for boundary value problem of nonlinear fractional differential equations, Electron. J. Differ. Equ., no. 36, (2006), pp. 1-12.

[21] X. ZHAO, W. GE, Unbounded solutions for a fractional boundary value problem on the infinite interval, Acta. Appl. Math, 109, (2010), pp. 495-505. 